Cahiers $d u$ MONDE RUSSE

\section{Cahiers du monde russe}

Russie - Empire russe - Union soviétique et États indépendants

$49 / 4 \mid 2008$

Destins individuels et terreur. Jeunesse dans la société post-stalinienne

\title{
Franziska Schedewie, Selbstverwaltung und sozialer Wandel in der russischen Provinz
}

\section{Sandra Dahlke}

\section{(2) OpenEdition \\ Journals}

Édition électronique

URL : https://journals.openedition.org/monderusse/6935

DOI : 10.4000/monderusse. 6935

ISSN : $1777-5388$

Éditeur

Éditions de l'EHESS

\section{Édition imprimée}

Date de publication : 28 décembre 2008

Pagination : 734-736

ISBN : 978-2-7132-2197-2

ISSN : $1252-6576$

Référence électronique

Sandra Dahlke, « Franziska Schedewie, Selbstverwaltung und sozialer Wandel in der russischen Provinz », Cahiers du monde russe [En ligne], 49/4 | 2008, mis en ligne le 23 décembre 2009, consulté le 03 septembre 2022. URL : http://journals.openedition.org/monderusse/6935; DOI : https://doi.org/ $10.4000 /$ monderusse. 6935

Ce document a été généré automatiquement le 3 septembre 2022.

Tous droits réservés 


\title{
Franziska Schedewie, Selbstverwaltung und sozialer Wandel in der russischen Provinz
}

\author{
Sandra Dahlke
}

\section{RÉFÉRENCE}

Franziska SCHEDEWIE, Selbstverwaltung und sozialer Wandel in der russischen

Provinz Bauern und Zemstvo in Voronez, 1864-1914. Heidelberg : Universitätsverlag Winter, 2006, 473 p. (Heidelberger Abhandlungen zur Mittleren und Neueren Geschichte, vol. 15).

1 L'étude de Franziska Schedewie porte sur les changements sociaux dans les villages russes entre 1864, année de la réforme des institutions de l'autoadministration locale et de la création des zemstva, et le début de la guerre en 1914. Il s'agit d'une analyse méticuleuse de la participation paysanne à la nouvelle institution du zemstvo dans quatre uezdy du gouvernement de Voronež, typique selon Schedewie de la partie russe de l'empire (Bobrov, Ostrogorsk, Voronež, Zemljansk). Comment les paysans ont-ils utilisé ces nouvelles institutions afin de formuler et de promouvoir leurs propres intérêts? Quelles en furent les conséquences pour la vie paysanne? Tout en montrant de façon convaincante qu'un très grand nombre de paysans participèrent activement au travail des zemstva et furent prêts à s'adapter aux mécanismes de l'autoadministration, l'auteur remet en question un discours dominant sur la paysannerie russe. Conçu par des nobles, des intellectuels, des fonctionnaires éclairés du tsar et reproduit par des générations d'historiens, ce dernier impose l'image d'une paysannerie arriérée, passive, traditionnelle, égalitariste, communautaire, à la fois antiétatique et anticapitaliste.

2 Schedewie critique cette conception paternaliste qui poursuit deux objectifs contradictoires. D'une part, protéger les paysans des conséquences négatives d'une modernisation considérée comme trop rapide; de l'autre, les intégrer dans les 
institutions d'un État moderne. L'auteur appuie son argumentaire sur des sources qui lui permettent de restituer le point de vue des paysans eux-mêmes. Elle explore minutieusement les statistiques des zemstva et surtout leurs journaux (žurnaly zemskago sobranija), source jusqu'à présent rarement utilisée, en retraçant au quotidien le travail de cet organisme et de ses différents sous-comités. Ces journaux contiennent des comptes rendus de réunions des zemstva, de la correspondance entre zemstvo et institutions d'État, enfin de nombreuses pétitions envoyéespar des paysans. Ceux-ci étaient en contact avec les zemstva à plusieurs titres: en tant que délégués ou représentants élus, bénéficiaires d'un crédit, entrepreneurs ou partenaires de contrat, contribuables, demandeurs, etc.

3 L'ouvrage est organisé en quatre chapitres. Le premier porte sur les sources et la méthodologie. Le deuxième analyse ce que Schewedie nomme les facteurs extérieurs modulant le degré de participation des paysans aux zemstva. L'auteur constate ici une forte corrélation entre participation aux nouvelles formes d'autoadministration et conditions géographiques et socio-économiques des différents uezdy du gouvernement : les paysans situés à proximité des marchés et bénéficiaires d'une infrastructure avancée furent en effet parmi les plus actifs dans les zemstva. Les anciens paysans d'État, ainsi que les descendants des odnodvorcy [alleutiers] et des cosaques, furent en général plus disposés à négocier leurs intérêts auprès des zemstva que les anciens serfs des propriétaires nobles qui restaient trop dépendants de l'attitude paternaliste de leurs maitres pour servir leurs propres intérêts. Dans ce dernier groupe, seuls ceux qui eurent à souffrir des mesures de modernisation eurent tendance à profiter des nouvelles institutions de l'autoadministration.

4 Le troisième chapitre traite des facteurs internes aux zemstva qui déterminaient la participation paysanne : cadre juridique et électoral, réalités fiscales. L'auteur montre que les paysans furent plus nombreux que les représentants des autres états à prendre part aux élections et plus assidus aux réunions. Ainsi, malgré la réduction de la représentation paysanne aux zemstva, introduite par la loi électorale de 1890, ils constituaient souvent de facto la majorité dans les réunions, ce qui leur permit parfois d'influencer le résultat des votes. En outre, ils s'avéraient plus disposés à payer leurs impôts que leurs homologues nobles. En termes de contenu, les propositions, demandes et projets que les paysans soumettaient avec leurs communes aux zemstva concernaient le plus souvent des aspects concrets de la vie communautaire et économique, comme la construction et le maintien de l'infrastructure, écoles et hôpitaux, l'amélioration de l'accès aux marchés, etc.

5 Le quatrième chapitre est le plus intéressant. Schedewie y explore les contributions des délégués paysans aux réunions des zemstva ainsi que leurs interactions avec les représentants des autres états. Qui étaient ces délégués? D'une manière générale, les paysans élisaient leurs représentants selon un critère de prestige social. C'étaient souvent des notables, starosty, fonctionnaires ou paysans aisés qui avaient déjà l'habitude de faire valoir leurs intérêts auprès des institutions extérieures au village. Schedewie identifie deux de leurs stratégies de communication. Certains étaient au même niveau économique leurs collègues nobles et eurent tendance à imiter leur comportement en s'investissant dans des travaux d'utilité publique ou le mécénat. Mais cette velléité d'adaptation ne fut pas toujours couronnée de succès : souvent, les représentants nobles adoptaient par réaction une attitude paternaliste ou usaient de leur supériorité discursive pour remettre à leur place ces ambitieux. D'autres, par réaction à cette 
attitude, soulignaient à dessein leur appartenance au groupe paysan afin de se démarquer des représentants des privilégiés. Dans l'ensemble, les paysans firent preuve d'une étonnante capacité à endosser plusieurs rôles, s'approprier les identités les plus diverses et adopter des stratégies de communication multiples. En dépit de tout cela, les zemstva ne se transformèrent nullement, selon l'auteur, en forum de lutte des classes. Bien au contraire, les paysans s'adaptèrent finalement aux nouvelles règles, normes et modes de communication et acceptèrent, dans leur vaste majorité, les nouvelles institutions de l'autoadministration.

6 Au total, Schedewie évalue l'interaction entre paysans et non-paysans au sein des zemstva comme un processus très prometteur d'apprentissage, d'intégration réciproque et de conciliation sociale. À ses yeux, les insurrections violentes de l'année 1905 représentent plutôt une régression vers des formes de communication plus anciennes qu'une manifestation de lutte des classes. L'argument convainc, puisque les conflits eurent lieu surtout là où l'institution du zemstvo était la moins développée.

7 L'étude de Schedewie est innovante et très solidement argumentée. L'auteur revendique une réévaluation du préjugé classique selon lequel la population paysanne aurait refusé les règles d'un État moderne et été inintégrable en son sein.

8 La bibliographie est complète. L'ouvrage contient en annexe un vaste matériau statistique, dont un CD-Rom contenant des tableaux résumant les informations des 1482 pétitions paysannes adresséees aux zemstva étudiées par l'auteur. Seule l'utilisation excessive de termes russes rend la lecture parfois un peu difficile. 